\title{
The Reach and Feasibility of an Interactive Lung Cancer Screening Decision Aid Delivered by Patient Portal
}

\author{
Ajay Dharod ${ }^{1,2}$ Christina Bellinger ${ }^{3} \quad$ Kristie Foley $^{2}$ \\ ${ }^{1}$ Department of Internal Medicine, Section on General Internal \\ Medicine, Wake Forest School of Medicine, Wake Forest University, \\ Winston-Salem, North Carolina, United States \\ 2 Department of Implementation Science, Wake Forest School of \\ Medicine, Wake Forest University, Winston-Salem, North Carolina, \\ United States \\ ${ }^{3}$ Department of Internal Medicine, Section on Pulmonary, Critical Care, \\ Allergy and Immunology, Wake Forest School of Medicine, Wake Forest \\ University, Winston-Salem, North Carolina, United States \\ ${ }^{4}$ Department of Biostatistical Sciences, Wake Forest School of Medicine, \\ Wake Forest University, Winston-Salem, North Carolina, United States
}

Appl Clin Inform 2019;10:19-27.

\author{
L. Doug Case ${ }^{4}$ David Miller ${ }^{1,2}$
}

\section{Abstract}

Keywords

- electronic health records

- eligibility determination

- decision support techniques

- patient portals

- cancer early detection
Objective Health systems could adopt population-level approaches to screening by identifying potential screening candidates from the electronic health record and reaching out to them via the patient portal. However, whether patients would read or act on sent information is unknown. We examined the feasibility of this digital health outreach strategy. Methods We conducted a single-arm pragmatic trial in a large academic health system. An electronic health record algorithm identified primary care patients who were potentially eligible for lung cancer screening (LCS). Identified patients were sent a patient portal invitation to visit a LCS interactive Web site which assessed screening eligibility and included a decision aid. The primary outcome was screening completion. Secondary outcomes included the proportion of patients who read the invitation, visited the interactive Web site, and completed the interactive Web site.

Results We sent portal invitations to 1,000 patients. Almost all patients $(86 \%, 862$ ) $1,000)$ read the invitation, $404(40 \%)$ patients visited the interactive Web site, and 349 patients (35\%) completed it. Of the 99 patients who were confirmed screening eligible by the Web site, 81 made a screening decision (30\% wanted screening, 44\% unsure, 26\% declined screening), and 22 patients had a chest computed tomography completed. Conclusion The digital outreach strategy reached the majority of patient portal users. While the study focused on LCS, this digital outreach approach could be generalized to other health needs. Given the broad reach and potential low cost of this digital strategy, future research should investigate best practices for implementing the system.

\section{Background and Significance}

Lung cancer is responsible for over $25 \%$ of all cancer deaths in the United States, making it the leading cause of cancer death. ${ }^{1}$ In 2011, the National Lung Screening Trial (NLST) reported that screening high-risk patients with low-dose chest computed tomography decreased relative lung cancer mortality by $20 \%{ }^{2}$ In the years following, several national organizations including the American Cancer Society, the American College of Chest Physicians, and the United States received

August 16, 2018

accepted after revision

November 16, 2018 (c) 2019 Georg Thieme Verlag KG Stuttgart · New York
DOI https://doi.org/

$10.1055 / \mathrm{s}-0038-1676807$. ISSN 1869-0327. 
Preventive Services Task Force have endorsed annual lung cancer screening (LCS) for high-risk current and former smokers. $^{3-5}$

While LCS decreases lung cancer mortality, it also introduces risks in the form of false-positive test results that could lead to invasive procedures and complications. For this reason, the Centers for Medicare \& Medicaid Services (CMS) announced that it will cover LCS for high-risk current and former smokers with the requirement that all patients first have a shared decision-making discussion about the risks and benefits of screening. ${ }^{6,7}$ Notably, benefits and harms of screening vary substantially according to an individual's risk for developing lung cancer. ${ }^{8,9}$

While widespread recommendations for LCS have existed since $2014,{ }^{5,7}$ only approximately $4 \%$ of eligible Americans have been screened. ${ }^{10}$ Multiple barriers contribute to the limited uptake of LCS. First, many primary care providers are unfamiliar with LCS guidelines. ${ }^{11}$ Lewis et al performed a survey $^{12}$ of primary care providers and demonstrated only $47 \%$ of providers knew at least three of six guideline components for LCS with $24 \%$ not knowing any guideline components. Ersek et a ${ }^{13}$ surveyed family physicians and found most had incorrect knowledge about which organizations recommended screening with many physicians continuing to recommend chest X-rays for LCS. Not surprisingly, more than $50 \%$ of family physicians reported making 1 or no screening recommendations in the prior year. Second, the time demands of clinical practice interfere with clinicians' ability to educate patients about this new screening modality and engage in shared decision-making discussions. ${ }^{14,15}$ Third, many patients are unaware of LCS or that they qualify. ${ }^{16,17}$ Lastly, conducting the mandated in-person shared decision-making discussion is difficult given scheduling and care access limitations and the complexities of the varying risks and benefits of screening by individual risk factors.

New strategies are needed to address these provider, patient, and system barriers to LCS. The growing popularity of patient portals and mobile technologies offer novel opportunities for new interventions. Directly reaching out to patients to inform them of LCS and empower them to make a screening decision can address patient knowledge barriers and bypass many provider and system barriers. Patient portals provide a secure Web site where patients can login to access their health information such as laboratory results, upcoming appointments, medication information, and even medical notes. Additionally, patients can use the portal for bidirectional electronic communication with their medical providers. To receive the maximum payments from Medicare, federal "meaningful use" criteria require practices to demonstrate their patients use a portal, strongly incentivizing health systems to adopt and implement this technology. ${ }^{18-20}$ Although data are limited, recent studies suggest that approximately $50 \%$ of patients have an active patient portal account, and higher rates of adoption are expected in the next few years. ${ }^{21}$ Most portals also feature smartphone apps, a key feature since over $75 \%$ of American adults now own a smartphone. ${ }^{22-24}$ Furthermore, ownership of smartphones is as prevalent among underrepresented minority groups, and even $67 \%$ of those with annual household incomes less than $\$ 30,000$ or only a high school education have a smartphone. . $^{23,25}$

Rather than relying on busy providers to identify patients who might qualify for LCS and offer screening, health systems could query their electronic health records (EHRs) to identify potential screening candidates and reach out to them via the patient portal. Such an approach would extend the delivery of care beyond the confines of a traditional office visit. However, whether patients would act on information sent via the patient portal, or whether they would even read portal messages, is unknown.

\section{Objective}

We sought to determine the feasibility of a digital health strategy for LCS delivered via the patient portal independent of a medical visit. Our intervention uses an algorithm to identify screening candidates, engages these at-risk patients via the patient portal, and provides them with personalized risk assessments to help them make a screening decision and receive screening if desired.

\section{Methods}

\section{Study Design and Setting}

We conducted a single-arm pragmatic study in a large academic health system that included 4 hospitals and a network of over 70 community-based clinics located in 19 counties in North Carolina. All practices share a common EHR, Epic. In 2017, over 88,000 patients in the health system aged 55 to 77 years old had an activated patient portal account. The health system's Lung Screening program has been awarded the "Lung Cancer Screening Center of Excellence" designation by the Lung Cancer Alliance. ${ }^{26}$ It houses a LCS clinic staffed by a nurse practitioner who meets with patients for a shared decision-making visit, orders the LCS if appropriate, and follows up on test results. Since the study was completed, the health system has opened a second LCS program in one of its affiliated hospitals. This pragmatic study was approved by the Wake Forest Health Sciences Institutional Review Board (IRB00036974) with a waiver of signed informed consent given that the interactive Web site delivers guideline-recommended information consistent with usual care.

\section{EHR Algorithm to Identify Screening Candidates}

We developed an EHR algorithm to identify potential candidates for LCS based on age and smoking history. Because the accuracy of recorded smoking histories was uncertain, we only excluded patients who were recorded as being "never smokers" to capture as many potential candidates as possible. We then excluded patients who may not be appropriate for screening based on a prior history of lung cancer or those with a life-limiting comorbidity (receiving treatment for cancer within the last 12 months; taking a medication for dementia; or evidence of end-stage renal disease, cirrhosis, and congestive heart failure). 


\section{mPATH-Lung Interactive Web Site}

Interactive Web site design: Members of our team have previously developed and tested Web- and tablet-based decision aids for colorectal cancer screening. ${ }^{27-29}$ Based on this usertested design, we created a Web-based decision aid for LCS, called mPATH-Lung (mobile Patient Technology for Health Lung). Notably, mPATH-Lung did not replace shared decision making, but instead was designed to ensure patients were well informed of risks and benefits prior to in-person shared decision making with a medical provider. The interactive Web site is fully Web-based, requiring no download, and is functionally available on both desktop and mobile browsers (mpath.wakehealth.edu/lung). To keep the user interface simple and scalable for mobile devices, each screen displays a single question with large intuitive response buttons or freetext entry blanks ( - Fig. 1). Users first answer 8 questions to determine their eligibility for LCS based on the CMS criteria. ${ }^{30}$ If users are eligible for screening, the decision aid shows them a brief video reviewing the general benefits and risks of LCS that are mandated by CMS. ${ }^{7}$ Immediately after the video, the decision aid allows users to estimate their personal risks and benefits of LCS by answering 8 additional demographic and medical history items. The interactive Web site then uses a model we developed ${ }^{31}$ to determine and display the personalized risk-benefit screening information in an infographic format ( - Fig. 2). This model uses the validated Prostate, Lung, Colorectal, and Ovarian Cancer Screening Trial model of $2012^{32,33}$ to calculate lung cancer risk and a reanalysis of the NLST results to estimate harms and benefits. Participants not answering the additional optional items are shown the risks and benefits of screening for the average-risk participant in the NLST. 2,31,34-36 The program closes by asking users if they would like to receive screening, and it gives users who respond "yes" or "maybe" the telephone number for the LCS clinic, staffed by a nurse practitioner, to schedule an appointment if they would like screening or more information. Prior to screening, patients meet with the nurse practitioner for an in-person shared decision-making visit.

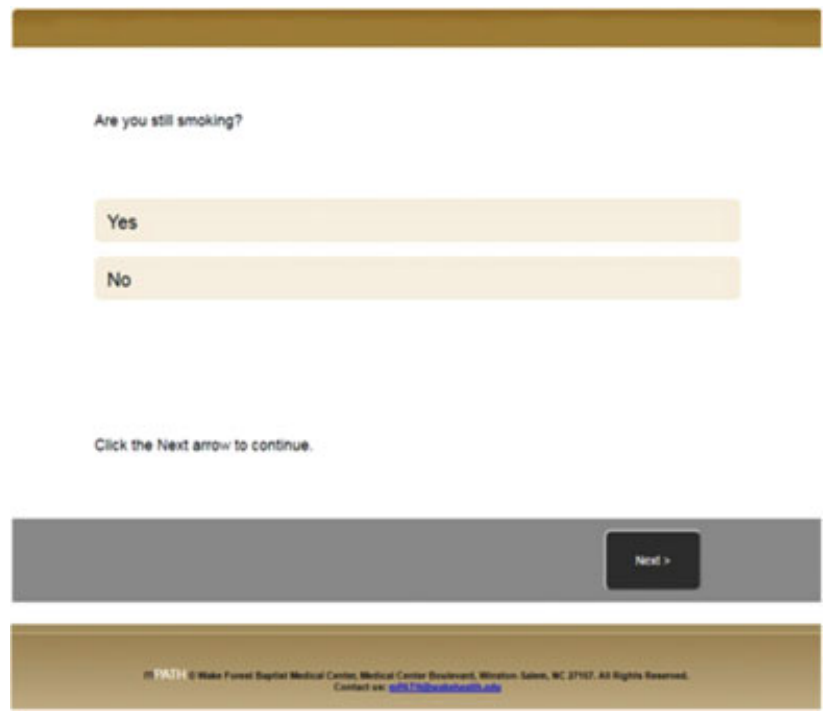

Fig. 1 Example screenshot of mPATH-Lung patient-reported information.

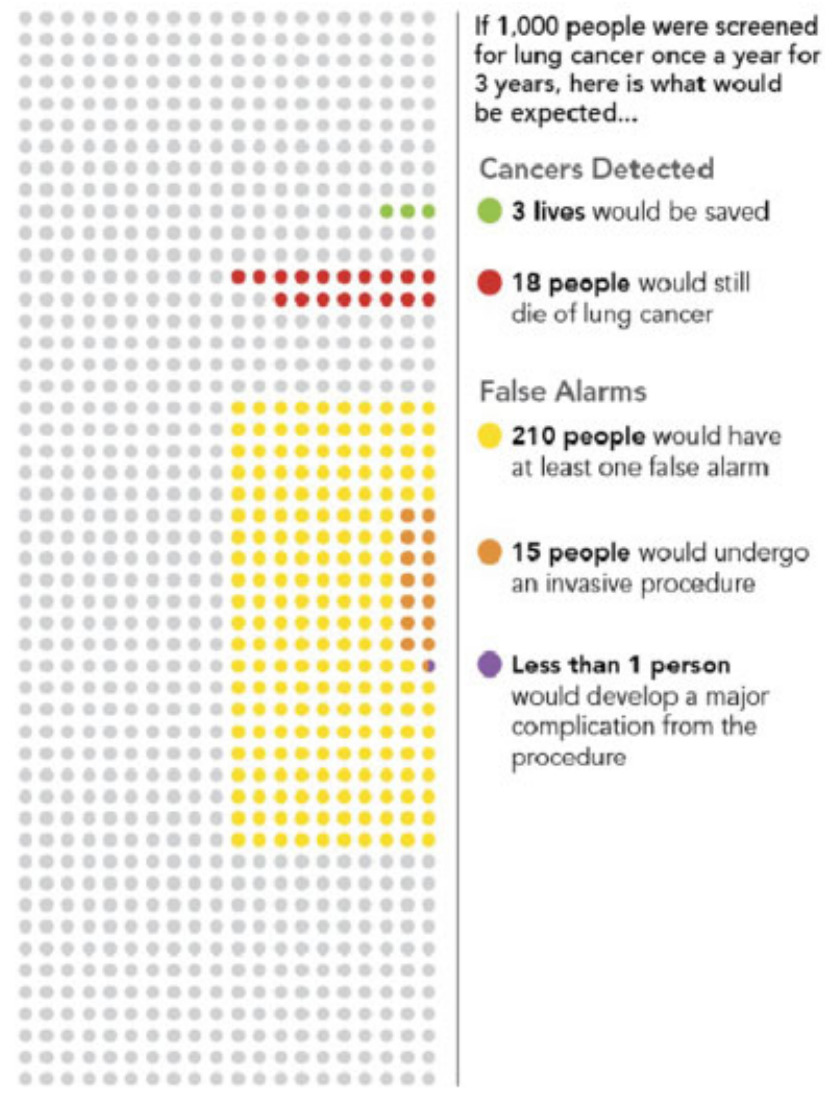

Fig. 2 Example screenshot of mPATH-Lung personalized risk-benefit information.

\section{Study Sample}

We ran the EHR algorithm weekly to identify potential screening candidates who were scheduled to see a Wake Forest primary care provider in the next 4 weeks and had logged into their patient portal account within the last 90 days. A research assistant then sent these patients an electronic message via the patient portal that displayed in their inbox as being sent from the "mPATH Team." No other information was visible to the patient until the message was opened. Once opened, the message stated, "A new screening test can significantly lower a person's chance of dying from lung cancer. An automated analysis of your Wake Forest Baptist Health record indicates you may qualify for this test. To learn more, click <hyperlink>" where the hyperlink contained a unique study identifier and took the user directly to the mPATH-Lung landing page. The message did not reference the patient's primary care practice or provider.

\section{Outcome Measures}

Our primary outcome of interest was the proportion of screening eligible participants who completed LCS within 4 months (120 days) of the sent portal invitation. Secondary outcomes included the reach of this digital-based approach to screening (defined as the proportion of invited participants who visited and completed the MPATH-Lung eligibility items), the proportion who read the portal message 
(defined as opening the message in the patient portal) as captured by the EHR logs, screening decisions made, and screening clinic appointments scheduled. A visit to MPATHLung was defined as clicking on the hyperlink in the patient portal message. We defined completion of the interactive Web site as answering all LCS eligibility questions, at which point mPATH-Lung either informs patients they are ineligible for screening, or if eligible, displays the LCS decision aid video. The Web site recorded time of visit and answers to all questions, and we determined which participants visited the Web site via the unique study ID embedded within each user's hyperlink.

\section{Statistical Analysis}

Our target sample size of 1,000 participants was chosen to provide a narrow $95 \%$ confidence interval $( \pm 3 \%)$ around our primary and secondary outcomes. Chi-square tests were used to assess differences in patient characteristics between those who did and did not read the portal message and between those who did and did not visit the interactive Web site. Statistical analyses were completed using SAS version 9.4. All analyses were based on intention to treat.

\section{Results}

Between November 2016 and February 2017, we sent 1,000 patient portal invitations to study participants. Of the messages sent, three were never received by the patient due to technical errors but were retained in our data set per intention-to-treat principle. Mean age was 65 years; 49\% were male. Baseline characteristics of the study participants are noted in -Table 1 .

\section{Messages Read and mPATH-Lung Visits}

Out of 1,000 messages sent, 862 (86\%) were read by participants. A total of $40 \%(404 / 1,000)$ visited the interactive Web site (-Fig.3). A similar percentage read the messages regardless of age, gender, insurance status, or smoking status ( - Table 1 ). The likelihood of reading the message varied by race/ethnicity, but a similar proportion visited the interactive Web site regardless of race/ethnicity. Only gender was associated with MPATH-Lung visits, with women being more likely to visit the interactive Web site than men ( $48 \%$ vs. $33 \%, p<0.05$ ).

-Fig. 4 illustrates the percentage of the study sample who read the message and who visited mPATH-Lung over time (from 0 to 120 days). The number of days to read the portal

Table 1 Baseline demographic characteristics of study sample

\begin{tabular}{|c|c|c|c|c|c|}
\hline \multirow[t]{2}{*}{ Characteristic } & \multirow{2}{*}{$\begin{array}{l}\text { Total sample } \\
\%(n)\end{array}$} & \multicolumn{2}{|c|}{ Read portal message $^{a}$} & \multicolumn{2}{|c|}{ Visited interactive Web site ${ }^{a}$} \\
\hline & & $\%(n)$ & $p$-Value & $\%(n)$ & $p$-Value \\
\hline Total & $100(1,000)$ & $86(862 / 1,000)$ & & $41(404)$ & \\
\hline Age $(y)$ & & & NS & & NS \\
\hline $55-59$ & $27(272)$ & $83(225)$ & & $35(94)$ & \\
\hline $60-64$ & 24 (239) & $86(206)$ & & $42(100)$ & \\
\hline $65-69$ & $25(247)$ & $88(217)$ & & $44(110)$ & \\
\hline $70-77$ & 24 (239) & $90(214)$ & & $42(100)$ & \\
\hline Race/Ethnicity & & & $<0.05$ & & NS \\
\hline Non-Hispanic White & $84(840)$ & $88(742)$ & & $41(343)$ & \\
\hline Non-Hispanic Black & $14(137)$ & $74(101)$ & & $40(54)$ & \\
\hline Hispanic & $1(9)$ & $100(9)$ & & $44(4)$ & \\
\hline Others & $1(11)$ & $91(10)$ & & $27(3)$ & \\
\hline Gender & & & NS & & $<0.05$ \\
\hline Male & $49(490)$ & $87(428)$ & & $33(163)$ & \\
\hline Female & $51(507)$ & $86(434)$ & & $48(241)$ & \\
\hline Insurance status & & & NS & & NS \\
\hline Commercial & $45(451)$ & $86(388)$ & & 39 (174) & \\
\hline Medicare & $51(512)$ & 87 (447) & & $43(218)$ & \\
\hline Medicaid & $2(19)$ & $84(16)$ & & $37(7)$ & \\
\hline Uninsured & $2(15)$ & $73(11)$ & & $28(5)$ & \\
\hline Smoking status & & & NS & & NS \\
\hline Current & 19 (186) & 85 (158) & & $44(82)$ & \\
\hline Former & $81(811)$ & 87 (704) & & $40(322)$ & \\
\hline
\end{tabular}

Abbreviation: NS, nonsignificant.

a Data abstracted at 120 days. 


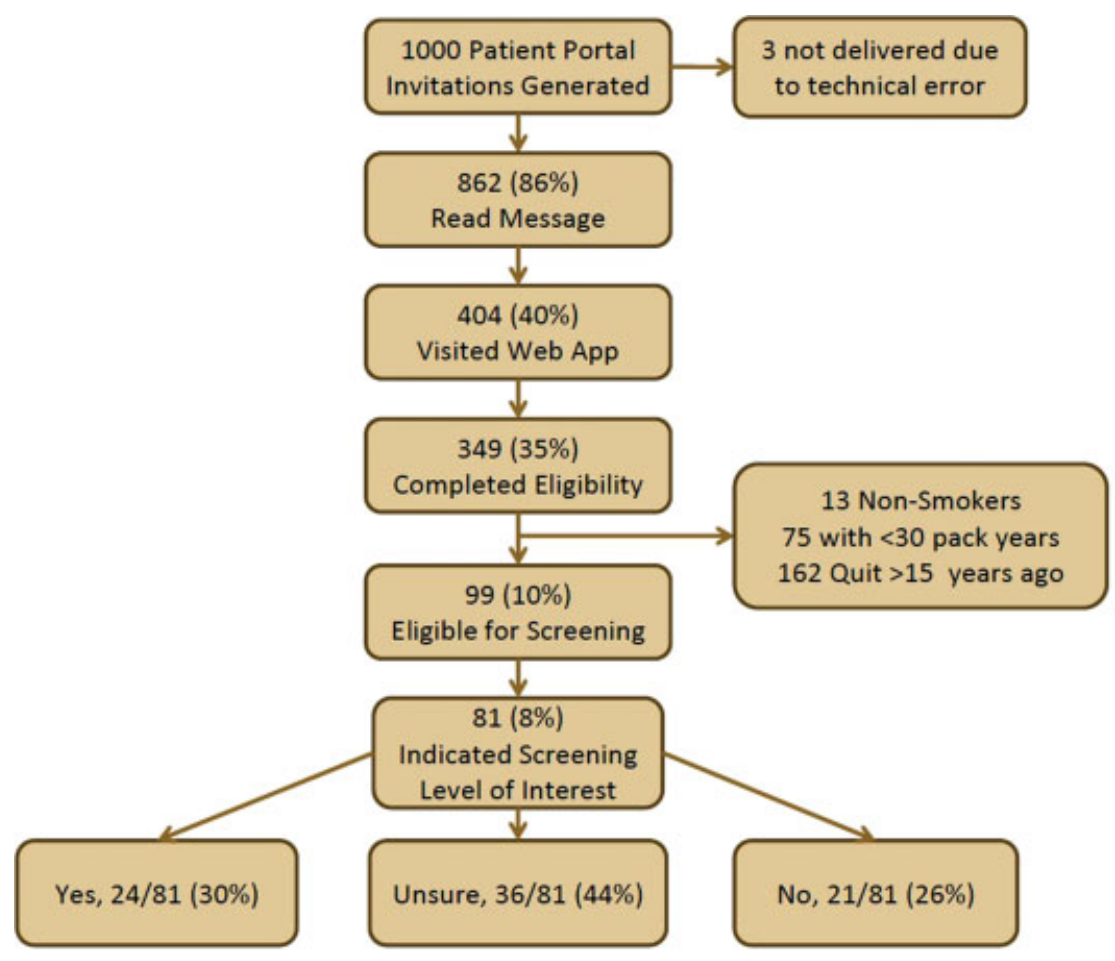

Fig. 3 Pragmatic trial flow diagram.

message (of those who read the message) ranged from 0 to 249 with a median of 0.7 days (or 17 hours). Of the 404 participants who visited the interactive Web site, the number of days from reading the portal message to visiting the app ranged from 0 to 75 with a median of 0.4 days (9.6 hours). Among participants who visited mPATH-Lung, almost all (96\%) visited it within 1 day of reading the message.

\section{Completion of mPATH-Lung}

Of the 404 patients who visited the interactive Web site, $86 \%$ (349/404) completed the core components. Ninety-nine of the completers were eligible for screening. Of the 250 participants ineligible for screening, 13 (5\%) were nonsmokers, 75 (30\%) had < 30 pack years, and 162 (65\%) quit smoking $>15$ years ago.

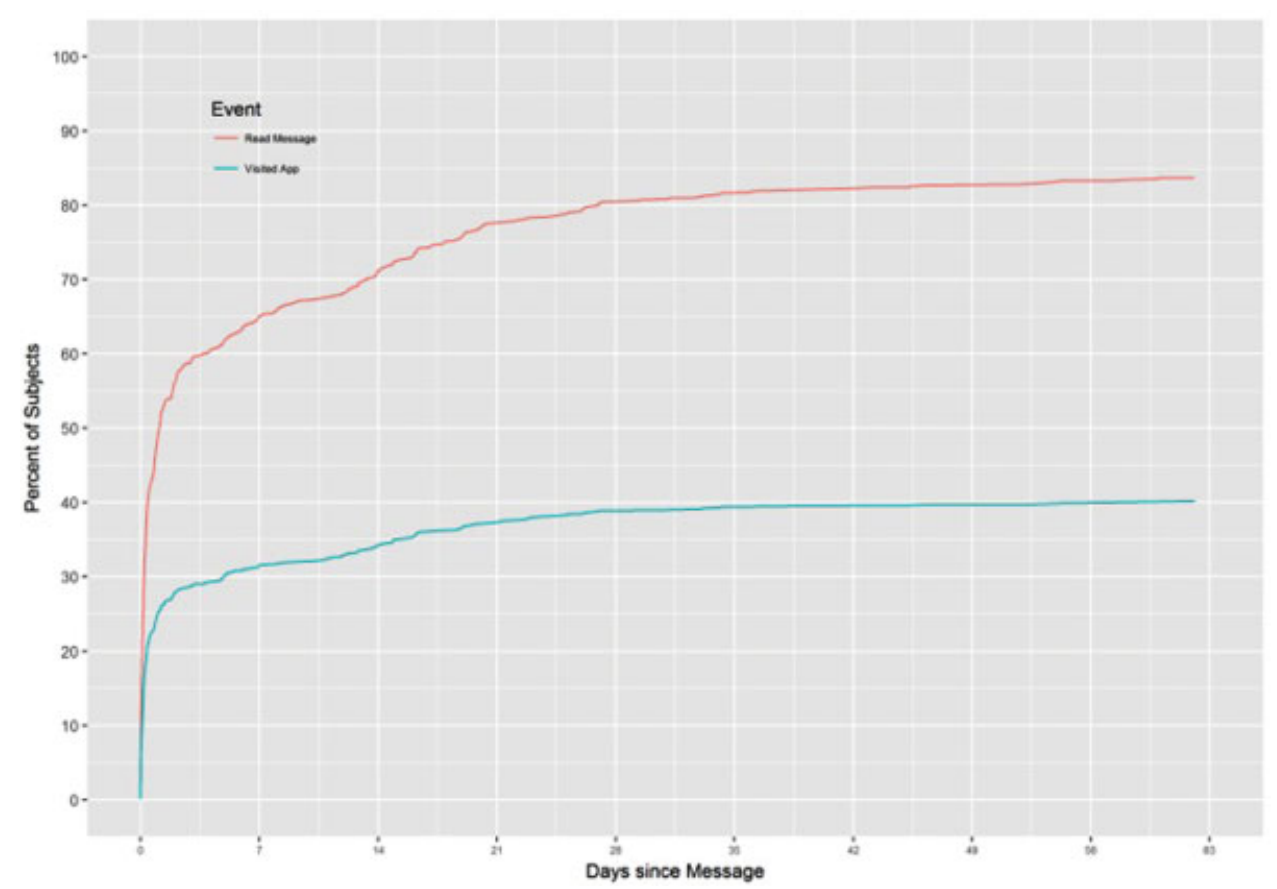

Fig. 4 Time to event plot showing \% of sample who read the message and \% of sample who visited the Web app over time (from 0 to 120 days). 


\section{Screening Decisions}

A total of 81 screening eligible participants indicated a screening decision (24 selected "Yes," 36 selected "Maybe," and 21 selected "No"). In a post hoc analysis, an individual's risk of developing lung cancer was not associated with a decision to receive screening. The median (range) risk for developing lung cancer for participants who wanted screening was $4.2 \%$ (1.5-13.7\%), for those who stated "Maybe" was $3.5 \%(0.4-21.5 \%)$, and for those who stated "No" was $2.1 \%$ (0.6-13.4\%), $p=0.09$.

\section{LCS Orders and Completion}

-Table 2 depicts chest CT orders and completion stratified by study participants who did not read the patient portal invitations, read the invitation but did not visit the mPATH-Lung, and those who visited the interactive Web site. Only 1 to $5 \%$ of patients completed an LCS clinic visit or completed any chest CT scan, and these proportions did not differ whether patients read the portal message or visited mPATH-Lung. More patients completed an LCS than those who visited the LCS clinic because primary care providers could complete shared decision making and order screening independent of the LCS clinic. Five of the 24 patients (21\%) who expressed a desire to be screened had a chest CT completed (-Table 3 ).

\section{Discussion}

LCS decreases mortality yet is greatly underutilized, revealing a critical need for strategies to increase LCS among eligible individuals in the United States. Despite guidelines recommending LCS for high-risk patients, multiple barriers limit its use. Our pragmatic trial demonstrates that a digital outreach strategy combining an EHR query with invitations sent via the patient portal has broad reach. Over $85 \%$ of

Table 2 Chest CT orders and completion ${ }^{a}$

\begin{tabular}{|l|l|l|l|}
\hline $\begin{array}{l}\text { Screening } \\
\text { outcome }\end{array}$ & $\begin{array}{l}\text { Did not read } \\
\text { message } \\
(\boldsymbol{n}=135)\end{array}$ & $\begin{array}{l}\text { Read message, } \\
\text { did not visit } \\
\text { mPATH-Lung } \\
(\boldsymbol{n}=458)\end{array}$ & $\begin{array}{l}\text { Visited } \\
\text { mPATH-Lung } \\
(\boldsymbol{n}=404)\end{array}$ \\
\hline $\begin{array}{l}\text { LCS clinic } \\
\text { visit } \\
\text { scheduled }\end{array}$ & $1(1 \%)$ & $3(1 \%)$ & $4(1 \%)$ \\
\hline $\begin{array}{l}\text { LCS clinic } \\
\text { visit } \\
\text { completed }\end{array}$ & $1(1 \%)$ & $3(1 \%)$ & $3(1 \%)$ \\
\hline $\begin{array}{l}\text { Any chest CT } \\
\text { completed }\end{array}$ & $5(4 \%)$ & $14(3 \%)$ & $22(5 \%)$ \\
\hline $\begin{array}{l}\text { Screening } \\
\text { or nodule } \\
\text { follow-up } \\
\text { chest CT } \\
\text { completed }\end{array}$ & $1(1 \%)$ & $6(1 \%)$ & $9(2 \%)$ \\
\hline $\begin{array}{l}\text { Other } \\
\text { chest CT } \\
\text { completed }\end{array}$ & $4(3 \%)$ & $8(2 \%)$ & $13(3 \%)$ \\
\hline
\end{tabular}

Abbreviations: $\mathrm{CT}$, computed tomography; LCS, lung cancer screening. ${ }^{\text {a All }} p$-values $>0.05$.
Table 3 LCS screening outcome compared with LCS interest

\begin{tabular}{|l|l|l|l|}
\hline \multirow{2}{*}{ Screening outcome } & \multicolumn{3}{|l|}{ LCS interest } \\
\cline { 2 - 4 } & $\begin{array}{l}\text { Yes } \\
(\boldsymbol{n}=\mathbf{2 4 )}\end{array}$ & $\begin{array}{l}\text { Maybe } \\
(\boldsymbol{n}=36)\end{array}$ & $\begin{array}{l}\text { No } \\
(\boldsymbol{n}=21)\end{array}$ \\
\hline $\begin{array}{l}\text { LCS clinic } \\
\text { visit scheduled }\end{array}$ & $2(8 \%)$ & $2(6 \%)$ & $0(0 \%)$ \\
\hline $\begin{array}{l}\text { LCS clinic } \\
\text { visit completed }\end{array}$ & $1(4 \%)$ & $2(6 \%)$ & $0(0 \%)$ \\
\hline $\begin{array}{l}\text { Screening or nodule } \\
\text { follow-up chest } \\
\text { CT completed }\end{array}$ & $3(13 \%)$ & $1(3 \%)$ & $0(0 \%)$ \\
\hline $\begin{array}{l}\text { Any chest } \\
\text { CT completed }\end{array}$ & $5(21 \%)$ & $3(8 \%)$ & $2(10 \%)$ \\
\hline
\end{tabular}

Abbreviations: CT, computed tomography; LCS, lung cancer screening.

patients in this trial read the portal invitation, and $40 \%$ visited mPATH-Lung. These high rates could partially reflect our inclusion criteria that limited the study to active portal users, defined as logging in to their accounts within the last 90 days. In addition, the health system's patient portal automatically notifies patients via email or text message whenever a new portal message is received. Once the message was opened and read, the message content indicating a potential for decreased chance of death was likely a strong motivator to click the embedded link and visit the interactive Web site. The high response rates we observed should be validated in other studies.

While approximately $50 \%$ of Americans use a patient portal, we recognize there are other more ubiquitous means to reach patients, such as telephone or text message. Currently, 95\% of adults have a cellular telephone with $77 \%$ owning a smartphone (including 74\% of those aged 50-64), and smartphone ownership is increasing yearly. ${ }^{35}$ Adding text messages to our digital strategy could increase its reach further. Moreover, digital outreach strategies require less time and fewer personnel resources than in-person phone calls.

EHR data, nationally and internationally, is known for relatively poor data quality. ${ }^{37-39}$ Constructing EHR selection algorithms require balancing sensitivity (identifying those who qualify for a service) with specificity (excluding those who do not qualify). We favored sensitivity over specificity given the minimal burden of having patients visit mPATHLung to determine if they qualify for screening. Therefore, we specifically designed our EHR algorithm to include eversmokers instead of more granular smoking history elements of pack-years or quit-years. This approach led to a large proportion (72\%) of participants determined ineligible for LCS upon visiting the mPATH-Lung interactive Web site. If this proportion was viewed as too high, our EHR algorithm could be easily modified to increase its specificity, but more individuals who qualify for screening would be missed.

Because mPATH-Lung resides on the Internet and can be used at home, it can be scaled easily without disrupting clinic flow. The Web site currently ends by referring interested patients to Wake Forest's LCS clinic, but we plan to revise this to assist visitors from other geographic regions. Our EHR 
query to identify potential screening candidates could also be revised to match a health system's data architecture. Our team is currently working on an approach to automate the sending of the portal messages, a process we handled manually for this current study.

Many factors influence patients' decisions to pursue LCS. In our study, we found the risk for developing lung cancer was not significantly different among those who wanted, did not want, or were not sure they wanted screening, suggesting factors other than absolute risk alone drive patients' screening decisions. This study was not designed to evaluate factors influencing patients' decisions to pursue or defer LCS; however, one survey study and two qualitative studies found that patients consider several factors in such decisions, including the mortality benefit, chance of false positives, emotional (anxiety) factors, and practical barriers (costs, transportation). ${ }^{17,40,41}$ LCS decision aids can help patients weigh these factors and make decisions concordant with their values. ${ }^{42-44}$

The gap between patients who indicated a desire for screening and those who completed screening in our trial indicates a need for additional patient support. This gap has been found in other studies of cancer screening decision aids. ${ }^{27}$ In our study, patients indicated screening preference, but were not able to directly schedule a screening visit. Allowing patients to schedule their own LCS clinic visits via the interactive Web site or automatically alerting primary care physicians that a patient is eligible could facilitate screening, as was seen in another trial in which patients could "order" their own screening. ${ }^{29}$

Our study has limitations. Our use of a single-arm pragmatic design yielded important information about the feasibility and reach of the digital outreach strategy, but our ability to examine its effectiveness for screening completion is limited by the absence of a control group. We are planning a future randomized study to examine this important outcome. There were also a relatively small number of Medicaid and uninsured individuals in our study sample. Completion of screening was determined by electronic review of the EHR and would miss any screening completed outside our institution. However, given the paucity of screening programs in the region, we believe this is unlikely. Additionally, the study was conducted within a single health care system with participants who were active portal users. The effect of the intervention could be different in different populations. Lastly, the study lacks power to detect differences within smaller subgroups.

\section{Conclusion}

A significant proportion of patients act on health information delivered via the patient portal. In this pragmatic study, over $85 \%$ of patients read the portal messages and $40 \%$ acted by visiting the screening interactive Web site. While our study focused on LCS, this digital outreach approach could be generalized to other health needs. Importantly, systematically querying the electronic medical record and sending messages to patients who may benefit from a service requires little staff time. Given the broad reach and potential low cost of this digital strategy, future research should investigate best practices for implementing similar systems in diverse health care settings.

\section{Clinical Relevance Statement}

Given the high prevalence of smartphone ownership and Internet use, online patient portals have the potential to broadly engage large numbers of patients in their care. Our study demonstrates that almost all patients read a healthrelated message that was sent to their portal account, and almost half of patients acted on the delivered information. This digital outreach approach could be applied to any health condition to inform patients and coordinate care delivery.

\section{Multiple Choice Questions}

1. What percentage of U.S. adults with annual household incomes less than $\$ 30,000$ or only a high school education have a smartphone?
a. About 67\%.
b. About $50 \%$.
c. About $25 \%$.
d. Less than $10 \%$.

Correct Answer: The correct answer is option a. Smartphone ownership is very prevalent in the United States. According to a survey conducted by the Pew Research Center in January 2018, even two-thirds of adults with annual household incomes less than $\$ 30,000$ or only a high school education have a smartphone.

2. What proportion of patients in this study read the patient portal message and visited the lung cancer screening interactive Web site?
a. $86 \%$.
b. $40 \%$.
c. $26 \%$.
d. $4 \%$.

Correct Answer: The correct answer is option b. Almost all patients ( $86 \%$ ) read the message that was sent to their patient portal account, and $40 \%$ of patients visited the lung cancer screening interactive Web site. These findings demonstrate the potential for health systems to reach large numbers of patients via the patient portal.

Note

This work has been presented in oral poster format at the Society of General Internal Medicine National Meeting in the category of Innovations in Clinical Practice in Washington DC (April 2017). No elements of this work have been published elsewhere and the paper article is not under consideration at other journals.

Protection of Human and Animal Subjects

The study was performed in compliance with the World Medical Association Declaration of Helsinki on Ethical Principles for Medical Research Involving Human Subjects, 
and was reviewed and approved by Wake Forest School of Medicine Institutional Review Board (IRB00036974). The study is on ClinicalTrials.gov (Identifier: NCT02962115; URL: https://clinicaltrials.gov/ct2/show/NCT02962115).

\section{Funding}

This study received funding from the Wake Forest University Comprehensive Cancer Center (NCI CCSG P30CA012197) and the Wake Forest Clinical and Translational Science Institute (NCATS UL1TR001420).

\section{Conflict of Interest}

None declared.

\section{Acknowledgment}

The authors would like to acknowledge the efforts of Donna Lawler as the study coordinator and Don Babcock, PE, who programmed mPATH-Lung.

\section{References}

1 Siegel RL, Miller KD, Jemal A. Cancer statistics, 2016. CA Cancer J Clin 2016;66(01):7-30

2 Aberle DR, Adams AM, Berg CD, et al; National Lung Screening Trial Research Team. Reduced lung-cancer mortality with lowdose computed tomographic screening. N Engl J Med 2011;365 (05):395-409

3 Smith RA, Manassaram-Baptiste D, Brooks D, et al. Cancer screening in the United States, 2015: a review of current American cancer society guidelines and current issues in cancer screening. CA Cancer J Clin 2015;65(01):30-54

4 Detterbeck FC, Mazzone PJ, Naidich DP, Bach PB. Screening for lung cancer: Diagnosis and management of lung cancer, 3rd ed: American College of Chest Physicians evidence-based clinical practice guidelines. Chest 2013;143(5, Suppl):e78S-e92S

5 Moyer VA; U.S. Preventive Services Task Force. Screening for lung cancer: U.S. Preventive Services Task Force recommendation statement. Ann Intern Med 2014;160(05):330-338

6 Lung cancer screening | Medicare.gov. Available at: https://www. medicare.gov/coverage/lung-cancer-screening.html. Accessed August 18, 2017

7 Centers for Medicare \& Medicaid Services. "Decision memo for screening for lung cancer with low dose computed tomography (LDCT)(CAG-00439N)." 2015 [2015-03-02]. Available at: http:// www.cms.gov/medicare-eoverage-data-base/details/nca-decisionmemo.aspx. Accessed December 5, 2018

8 Kovalchik SA, Tammemagi M, Berg CD, et al. Targeting of low-dose CT screening according to the risk of lung-cancer death. N Engl J Med 2013;369(03):245-254

9 Pinsky PF, Bellinger CR, Miller DP Jr. False-positive screens and lung cancer risk in the National Lung Screening Trial: implications for shared decision-making. J Med Screen 2018;25(02): $110-112$

10 Jemal A, Fedewa SA. Lung cancer screening with low-dose computed tomography in the United States-2010 to 2015. JAMA Oncol 2017;3(09):1278-1281

11 Kanodra NM, Pope C, Halbert CH, Silvestri GA, Rice LJ, Tanner NT. Primary care provider and patient perspectives on lung cancer screening. A qualitative study. Ann Am Thorac Soc 2016;13(11): 1977-1982

12 Lewis JA, Petty WJ, Tooze JA, et al. Low-dose CT lung cancer screening practices and attitudes among primary care providers at an academic medical center. Cancer Epidemiol Biomarkers Prev 2015;24(04):664-670
13 Ersek JL, Eberth JM, McDonnell KK, et al. Knowledge of, attitudes toward, and use of low-dose computed tomography for lung cancer screening among family physicians. Cancer 2016;122(15):2324-2331

14 Yarnall KSH, Pollak KI, Østbye T, Krause KM, Michener JL. Primary care: is there enough time for prevention? Am J Public Health 2003;93(04):635-641

15 Østbye T, Yarnall KSH, Krause KM, Pollak KI, Gradison M, Michener JL. Is there time for management of patients with chronic diseases in primary care? Ann Fam Med 2005;3(03):209-214

16 Simmons VN, Gray JE, Schabath MB, Wilson LE, Quinn GP. Highrisk community and primary care providers knowledge about and barriers to low-dose computed topography lung cancer screening. Lung Cancer 2017;106:42-49

17 Carter-Harris L, Brandzel S, Wernli KJ, Roth JA, Buist DSM. A qualitative study exploring why individuals opt out of lung cancer screening. Fam Pract 2017;34(02):239-244

18 Marcotte L, Seidman J, Trudel K, et al. Achieving meaningful use of health information technology: a guide for physicians to the EHR incentive programs. Arch Intern Med 2012;172(09): 731-736

19 Medicare C for. Baltimore MS 7500 SB, Usa M. PaymentAdj_Hardship; 2017. Available at: https://www.cms.gov/Regulations-and-Guidance /Legislation/EHRIncentivePrograms/PaymentAdj_Hardship.html. Accessed August 18, 2017

20 Goldzweig CL, Orshansky G, Paige NM, et al. Electronic patient portals: evidence on health outcomes, satisfaction, efficiency, and attitudes: a systematic review. Ann Intern Med 2013;159(10):677-687

21 Smith SG, O'Conor R, Aitken W, Curtis LM, Wolf MS, Goel MS. Disparities in registration and use of an online patient portal among older adults: findings from the LitCog cohort. J Am Med Inform Assoc 2015;22(04):888-895

22 The evolution of technology adoption and usage. Pew Res. Cent; 2017. Available at: http://www.pewresearch.org/fact-tank/2017/ 01/12/evolution-of-technology/ft_17-01-10_internetfactsheets/. Accessed June 11, 2018

23 Mobile Fact Sheet. Pew Res. Cent. Internet Sci. Tech; 2017. Available at: http://www.pewinternet.org/fact-sheet/mobile/. Accessed August 18, 2017

24 Technology Device Ownership; 2015 » Public Libraries Online. Available at: http://publiclibrariesonline.org/2015/12/technology-device-ownership-2015/. Accessed August 18, 2017

25 Internet/Broadband Fact Sheet. Pew Res. Cent. Internet Sci. Tech; 2017. Available at: http://www.pewinternet.org/fact-sheet/internet -broadband/. Accessed August 18, 2017

26 Fuchs C. Screening Centers of Excellence Designation. Lung Cancer Alliance. Available at: https://lungcanceralliance.org/for-professi onals/screening-centers-of-excellence-designation/. Accessed June 18, 2018

27 Miller DP Jr, Spangler JG, Case LD, Goff DC Jr, Singh S, Pignone MP. Effectiveness of a web-based colorectal cancer screening patient decision aid: a randomized controlled trial in a mixed-literacy population. Am J Prev Med 2011;40(06):608-615

28 Miller DP Jr, Weaver KE, Case LD, et al. Usability of a novel mobile health iPad app by vulnerable populations. JMIR Mhealth Uhealth 2017;5(04):e43. Doi: 10.2196/mhealth.7268

29 Miller DP Jr, Denizard-Thompson N, Weaver KE, et al. Effect of a digital health intervention on receipt of colorectal cancer screening in vulnerable patients: a randomized controlled trial. Ann Intern Med 2018;168(08):550-557

30 Centers for Medicare \& Medicaid Services. Final National Coverage Determination on Screening for Lung Cancer with Low Dose Computed Tomography (LDCT)(CAG-00439N); 2015. Available at: https:// www.cms.gov/medicare-coverage-database/details/nca-decisionmemo.aspx? NCAId $=274$. Accessed November 10, 2015

31 Bellinger CR, Pinsky P, Foley KL, et al. A Lung cancer screening benefits and harms stratified by patient risk: information to improve patient decision aids. Ann Am Thorac Soc. Doi: White201810-690RL.R1 
32 Tammemägi MC, Katki HA, Hocking WG, et al. Selection criteria for lung-cancer screening. N Engl J Med 2013;368(08):728-736

33 Katki HA, Kovalchik SA, Petito LC, et al. Implications of nine risk prediction models for selecting ever-smokers for computed tomography lung cancer screening. Ann Intern Med 2018;169(01):10-19

34 Aberle DR, Berg CD, Black WC, et al; National Lung Screening Trial Research Team. The National Lung Screening Trial: overview and study design. Radiology 2011;258(01):243-253

35 Kramer BS, Berg CD, Aberle DR, Prorok PC. Lung cancer screening with low-dose helical CT: results from the National Lung Screening Trial (NLST). J Med Screen 2011;18(03):109-111

36 Church TR, Black WC, Aberle DR, et al; National Lung Screening Trial Research Team. Results of initial low-dose computed tomographic screening for lung cancer. N Engl J Med 2013;368(21):1980-1991

37 Botsis T, Hartvigsen G, Chen F, Weng C. Secondary use of EHR: data quality issues and informatics opportunities. AMIA Jt Summits Transl Sci Proc 2010;2010:1-5

38 Orfanidis L, Bamidis PD, Eaglestone B. Data quality issues in electronic health records: an adaptation framework for the Greek Health System. Health Informatics J 2004;10:23-36
39 Chan KS, Fowles JB, Weiner JP. Review: electronic health records and the reliability and validity of quality measures: a review of the literature. Med Care Res Rev 2010;67(05):503-527

40 Ali N, Lifford KJ, Carter B, et al. Barriers to uptake among high-risk individuals declining participation in lung cancer screening: a mixed methods analysis of the UK Lung Cancer Screening (UKLS) trial. BMJ Open 2015;5(07):e008254

41 Lillie SE, Fu SS, Fabbrini AE, et al. What factors do patients consider most important in making lung cancer screening decisions? Findings from a demonstration project conducted in the Veterans Health Administration. Lung Cancer 2017; 104:38-44

42 Lau YK, Caverly TJ, Cao P, et al. Evaluation of a personalized, webbased decision aid for lung cancer screening. Am J Prev Med 2015; 49(06):e125-e129

43 Reuland DS, Cubillos L, Brenner AT, Harris RP, Minish B, Pignone MP. A pre-post study testing a lung cancer screening decision aid in primary care. BMC Med Inform Decis Mak 2018;18(01):5

44 Fagerlin A, Pignone M, Abhyankar P, et al. Clarifying values: an updated review. BMC Med Inform Decis Mak 2013;13(Suppl 2):S8 